\title{
SCHOPENHAUER, ZOLA Y CLARÍN
}

\author{
Adolfo SOTELO VÁZQUEZ \\ Universitat de Barcelona
}

\begin{abstract}
"Dans la peine, dans la douleur, dans la souffrance, nous retrouvons, à l'état de pureté, le définitif, qui constitue la tragédie de la solitude"

(Emmanuel Levinas, Le temps et l'autre)
\end{abstract}

Las intertextualidades de la crítica y la novela francesa - y por su cauce del pensamiento europeo- con la crítica y la novela española durante la década de los ochenta del siglo pasado, en la que se debaten y analizan por primera vez en la historia de la literatura española, cuestiones que afectan a la construcción (discurso, relato) de la novela son de una frecuencia y de una magnitud tales que una de las tareas más urgentes y provechosas que se pueden emprender es ir abriendo surcos para su investigación. El presente surco trata de establecer el estímulo que el pensamiento de Schopenhauer supuso para Clarín en el momento de la génesis y elaboración de La Regenta, teniendo como nexo la narrativa de Émile Zola y, en especial, la novela La Joie de vivre, la decimosegunda de la serie Les Rougon Macquart, aparecida en los folletones del Gil Blas entre el 29 de noviembre de 1883 y el 3 de febrero de 1884, y publicada en tomo por Charpentier a finales del invierno de 1884. La incitación de su lectura y el conocimiento de la órbita filosófica que la rodeaba fue fundamental en la configuración del significado último de la obra maestra de Leopoldo Alas.

\section{I}

Al compás de los debates sobre el realismo (segunda mitad de los años setenta) y de la inicial recepción del naturalismo en España (1880-1882) se opera entre 
la intelectualidad española un tímido, pero nada despreciable interés por el pensamiento de Schopenhauer. Adelantado de este interés fue José del Perojo, alma mater de la Revista Contemporánea entre su fundación, en los últimos días de 1875, y 1879. José del Perojo, cubano que había estudiado en Heidelberg bajo el magisterio de Kuno Fischer - promotor del movimiento neokantiano- llamó la atención del mundo cultural español desde las páginas de la Revista Europea con una serie de artículos sobre la filosofía alemana -Kant, Heine, Schopenhaucr, etc.- que conformarían el tomo Ensayos sobre el movimiento intelectual en Alemania (Madrid, Medina y Navarro, (875)'. El impacto de los artículos de Perojo se advierte en las reseñas que motivó el tomo. Dos aparecieron en las revistas más prestigiosas de la España que vería nacer la Revista Contemporánea. Se trata de la que Manuel de la Revilla publica en la Revista de España bajo el título de "El neo-kantismo en España" (29-XI-1875) y la que Rafael Montoro da a la luz en la Revista Europea el 11 de octubre de 1875. A ellas hay que sumar la que Leopoldo Alas publica en la sección "Libros y Libracos" de El Solfeo (10 y 14-X-1875) y la que firma Urbano González Serrano en la prensa de la época - a buen seguro en la Revista de Instrucción Pública - y que recoge posteriormente en su obra Ensayos de crítica y de filosofia (Madrid, Aurelio J. Alaria, 1881).

El ensayo de Perojo sobre Schopenhauer es el primer acercamiento que conocen las letras españolas al pensamiento del filósofo de Frankfurt. El tono divulgativo no es obstáculo para que Perojo advierta en la filosofía del autor de Parerga y Paralipomena la expresión de un momento de la cultura europea irreemplazable en la construcción de la modernidad (que Perojo denominó siempre "lo contemporáneo"). Perojo, que emplea los textos originales alemanes y que está al tanto del estudio de Théodule Ribot, La Philosophie de Schopenhauer (Paris, Germer Baillière, 1874)², sitúa a Schopenhauer a la cabeza de las doctrinas del pesimismo contemporáneo, cuyas manifestaciones más relevantes no se localizan - según Perojo- en el campo filosófico o científico sino en "el libre y espontáneo" de poetas como Byron, Leopardi, Musset o Campoamor. Tras delinear ligeramente los rasgos característicos de su filosofía, reconoce su valor parcial como

$1 \quad C f$. Adolfo Sotelo Vázquez (1994, págs. 19-35). Estudio allí el destacado papel que Perojo cumplió en la divulgación en España de las ideas que nutren la estética realista y la escuela naturalista, atendiendo a la recepción de su obra Ensayos sobre el movimiento intelectual en Alemania. Puede leerse como pórtico del presente artículo.

2 El libro de Ribot es el primer asedio a Schopenhauer desde la órbita del pensamiento francés. Tanto Émile Bréhier como Frederick Copleston lo consideran la primera referencia bibliográfica sobre la filosofía de Schopenhauer, a la par que la primera antología francesa del filósofo alemán. Su función divulgadora del ideario de Schopenhauer entre los escritores naturalistas fue continuada por el libro de Elme-Marie Caro, Le Pessimisme au XIX siècle (Paris, 1878) -más famoso entre los literatos debido al polémico compte rendu de Ferdinand Brunetière en la Revue des Deux Mondes (15-1-1879)- y por artículos como el de Charles Richet, "La douleur", publicado en la prestigiosa Revue Philosophique (1877). Para mayor información el lector puede consultar dos libros beneméritos: A. Baillot (1927), y René Pierre Colin (1979). Debo recordar que la segunda edición del libro de Ribot apareció editada por Alcan en 1888. Cf. Didier Raymond (1979). 
"la expresión psicológica de un momento de nuestra cultura contemporánea, y mejor aún, como un espejo, aunque parcial, que reflejara a las generaciones venideras gran parte de nuestra vida que de otro modo permanecería totalmente oculta, o lo sumo atribuida a la fantástica imaginación de los poetas. Este es, pues, uno de los valores que hay que reconocer a Schopenhauer, y que, unido a la belleza y riqueza de su estilo, profundidad de pensamiento, constituyen tres cualidades, cultura histórica, estética y filosófica, las cuales no permiten su olvido, y le aseguran un puesto eminente entre los primeros pensadores de nuestro siglo".

El trabajo de Perojo, saludado unánimente por los críticos que antes mencioné como pórtico de una necesaria aproximación al pensamiento europeo, no concitó la misma unanimidad crítica en lo que se refiere a su valoración de la filosofía de Schopenhauer. El entusiasmo de Perojo fue sancionado por Manuel de la Revilla (1875, pág. 150) con el siguiente interrogante:

“Es justo conceder tantas atenciones al humorista Schopenhauer, y menospreciar a Fichte, a Hegel y a Krause?"

Al inteligente y malogrado crítico no le parecía imparcial y aquilatado el juicio de Perojo sobre Schopenhauer, cuya doctrina que calificaba de "mezcla inconcebible de kantianismo y budismo" no estaba llamada "a fundar nada sólido ni duradero, pues nunca han fundado ni fundarán nada los pesimistas y los extravagantes" (Revilla 1875, pág. 149).

Así mismo González Serrano, el crítico que más devoción profesaría por Schopenhauer al andar de los años hacia el fin de siglo, no se explicaba la atención y el aprecio que Perojo dispensaba al filósofo de Frankfurt:

"no nos explicamos (...) que el expositor de Schopenhauer ponga por las nubes a este pensador, cuando le compara con lo que llama la escuela idealista (...) No nos admira esta predilección" (González Serrano 1881, pag. 188).

Paralelamente González Serrano valoraba el pesimismo de Schopenhauer al modo de Revilla como una "originalidad indeterminada", consistente en "principios kantianos combinados ingeniosamente con enseñanzas budhistas" (González Serrano 1881, pág. 190).

A la luz de estas lacónicas referencias se debe consignar que la acogida inicial del pensamiento de Schopenhauer ni fue generosa ni entusiasta ${ }^{4}$. La admiración que destilaba el ensayo de Perojo no fue compartida por la crítica.

Cito el texto por José del Perojo (1875, pág. 408.)

4 Desde luego no emplearía estos calificativos si atendiese a las valoraciones que de Schopenhauer hizo años después González Serrano. No obstante, en la última que de su pluma conozco, el boceto filosófico que publicó en la Revista Contemporánea el 15 de mayo de 1902, aunque se se refiere a su "hondo humorismo" y a su "genio paradójico" con renovado entusiasmo, sigue sin convencerle el divorcio entre las ideas y la vida del filosófo, convencido el pensador krausopositivista de la superioridad de los buenos sobre los sabios, condición que, a su juicio, no cumplía el maestro del pesimismo. 
En ese mismo diapasón crítico se mueve Leopoldo Alas, quien en la reseña de la "joya de tantos quilates" que ha compuesto Perojo, no pasa de una mención de Schopenhauer sin el más mínimo justiprecio. Los más de quinientos artículos que dio a la luz antes de 1881, fecha de la primera edición de Solos, en El Solfeo y La Unión, no atienden nunca específicamente a Schopenhauer. Únicamente en el capítulo tercero de su tesis doctoral, El derecho y la moralidad (1878), al repasar el concepto del derecho en la historia de su filosofía trae a colación un fragmento de El mundo como voluntad y representación, procedente del capítulo LXII, en torno al derecho y la injusticia. No comparte el entonces muy ortodoxo krausista Leopoldo Alas la naturaleza del derecho que expone Schopenhauer; la considera equivocada y una formulación más en la trayectoria decadente y formalista en que ha degenerado el pensamiento kantianos.

Precisando un poco más los iniciales linderos de las referencias clarinianas al pesimismo de Schopenhauer se debe recordar que, al margen de esa mención en su tesis doctoral, las primeras e importantísimas alusiones de Alas a Schopenhauer se producen en dos artículos aparecidos en La Publicidad barcelonesa el 11 de junio y el 16 de diciembre de 1880, con los respectivos títulos de "Cavilaciones" y "Más cavilaciones", incluidos posteriormente en Solos (1881). Entre estos artículos, el primero de los cuales ya había visto la luz en la Revista de Asturias el 15 de febrero de 1881, publica en La Publicidad (previamente lo había hecho el 15 de julio de 1879 en la Revista de Asturias y el 27 de julio en La Unión) el 7 de octubre de 1880 el artículo "El amor y la economía", en torno a la mujer y el matrimonio, en el que amalgamando el discurso grave y el festivo se refiere a la filosofía de Schopenhauer acerca de la metafísica del amor. Escribe Clarín:

"Un señor alemán muy excéntrico, y que tenía un apellido muy raro (ifigurénse Uds. que se llamaba Schopenhauer!, pronúncienlo Uds. como quieran, si no quieren abrir mucho la boca), dijo que los mejores matrimonios son esos que no se hacen por amor, sino por arreglo, porque en ellos no se sacrifica el individuo a la especie, como sucede en los consorcios por cariño, en los cuales, sin más fin que el de... Verán Uds.; esto se puede decir de muchas maneras... yo diré... arrullarse; pues bien, sin más fin que el de arrullarse estos esposos, olvidan su propio interés y trabajan inconscientemente por la especie, es decir, porque no se acabe el mundo"6.

Esta divertida reflexión de Alas tiene su punto de partida en un pasaje de los suplementos al cuarto libro, "El mundo como voluntad" de Die Welt als Wille und Vorstellung, según la segunda edición publicada en 1844 por el editor Brockhaus

5 Cf. Leopoldo Alas (1878, pág. 489).

- Yvan Lissorgues (1989, págs. 236-237). Del libro de mi admirado amigo tomo algunas precisiones cronológicas. 
de Leipzig. El pasaje (fragmentado) de Schopenhauer reza según la traducción francesa de Burdeau ${ }^{7}$ así:

"Les mariages d'amour sont conclus dans l'intérêt de l'espèce, et non des individus. Sans doute les personnes en jeu s'imaginent travailler à leur prope bonheur: mais leur but véritable leur est, en réalité, étranger à elles-mêmes, et consiste dans la création d'un individu qui n'est possible que par elles (...) Aussi, en règle générale, les mariages d'amour ont-ils une issue malheureuse, car ils pourvoient à la génération future aux dépens de la présente. Quien se casa por amores, ha de vivir con dolores, dit le proverbe espagnol. C'est l'inverse pour les mariages de convenence, conclus presque toujours d'après le choix des parents (...) L'homme qui, en se mariant, regarde plus l'argent qu'à la satisfaction de son penchant, vit plus dans l'individu que dans l'espèce" (Schopenhauer 1984, pág. 1316).

Así, pues, está claro que Leopoldo Alas a la altura de 1879 conoce, al menos en el esquematismo divulgado por Ribot, la filosofía de Schopenhauer. Más no creo que se pueda precisar, pero los textos de "Cavilaciones" hablan — 1881 — de un interés creciente por el pesimismo, lo que no supone en modo alguno que el idealista krausista que siempre fue Alas compartiese el irracionalismo metafísico de la filosofía de Schopenhauer. Por lo demás, me parece que Clarín fue el crítico cultural y literario que mejor entendió (cosa muy distinta es que lo compartiese) el pensamiento de Schopenhauer, pese a que su divulgación en la España del último cuarto del siglo XIX conoció mejores trabajos en las plumas de González Serrano y Antonio Zozaya ${ }^{8}$.

\section{II}

Esta exploración muy superficial de la inicial acogida del pensamiento de Schopenhauer en España no puede pasar por alto -en el caso de Clarín-- la no menos oportuna atención que el provinciano universal prestó a Zola. Sin entrar en detalles pormenorizados voy a situar el conocimiento y la inmediata fascinación del futuro autor de La Regenta por el novelista de L'Assommoir'.

7 Decía con cierta exageración Nietzsche en su panfleto Nietzsche contra Wagner (1888, pero publicado en 1900) que la obra maestra de Schopenhauer se había traducido al francés dos veces - la traducción de Cantacuzàne (1886) y la de Burdeau (1888) - y la segunda vez de un modo excelente, hasta el punto de señalar que leía a Schopenhauer en francés. Cf. Martin Gregor-Dellin (1983).

8 Quiero recordar aquí el excelente apéndice que bajo el marbete "El pesimismo sistemático" publicó Antonio Zozaya en su traducción de Arturo Schopenhauer, Parerga y Paralipomena. Aforismos sobre la sabiduría en la vida, Madrid, Biblioteca Económica Filosófica, 1889, t. 11, pp. 179-204. Es ésta buena ocasión para deshacer un entuerto acerca de la relación de Schopenhauer y España de notable gravedad. La traductora al español del excelente libro de Bryan Magee, The Philosophy of Schopenhauer (Madrid, Cátedra, 1991) afirma - página 7- que Parerga und Paralipomena carece de traducción española. Como se ve en la presente nota, Antonio Zozaya tradujo esta obra hace más de un siglo.

9 El interesado lector puede leer noticias complementarias (como la recepción de Solos) en mi conferencia "Urbano González Serrano y el Naturalismo", que está a punto de aparecer en las Actas del Coloquio Internacional celebrado en Lyon (IX, 1996) sobre Zola y España, que publica la Universitat de Barcelona (1997, en prensa). 
En un desatendido y olvidado "Palique autobiográfico" publicado por Clarín en La Publicidad (3-III-1882) el genial crítico asturiano ofrece al lector un peculiar Ecce homo en el que dice sin ambages: "baste saber que ahora soy en literatura naturalista" 10 . Para entonces había publicado Solos y la crítica más oportuna había saludado el libro como un heterogéneo abanico de críticas literarias trazadas desde una óptica naturalista; también para esas fechas (un mes antes) La Diana había empezado a publicar la aguda serie de atículos clarinianos rotulados "Del Naturalismo". En efecto, para principios de 1882 Clarín es un fervoroso e inteligente crítico que admira sinceramente la teoría y la práctica novelescas de Zola, aunque sostenga importantes discrepancias nacidas de su lealtad a los principios de la ética krausista.

¿Cuândo empezó Clarín a leer a Zola? En un "Palique" de Madrid Cómico (12-II-1898) en el que se refiere retrospectivamente a sus héroes y a sus lecturas, confiesa la fuerte impresión que le produjo Zola, a quien empezó a leer alrededor de 1879 , tras haber presentado su tesis doctoral:

“Empecé a leer a Zola por L'Assommoir. Estaba yo convaleciente de larga y penosa enfermedad. Estaba muy nervioso y tenía la imaginación muy viva y el discurso muy excitado, y en lo posible en mí, aguzado. L'Assommoir fue para mí una revelación de arte nuevo" (Alas 1973, pág. 190).

Como se ve Clarín se interesó por Zola al mismo tiempo que por Schopenhauer, si bien es verdad que el novelista francés supuso para su trayectoria crítica y narrativa un acicate de una importancia no comparable con la del filósofo alemán. Es más: creo que no sería excesiva ni aventurada la conjetura que sostuviese que la aproximación lectora de Alas al pesimismo sistemático viene catalizada por su pasión e interés por Zola y por el Naturalismo. El examen de Solos confirmaría la certeza de ese paralelismo y de ese estímulo, tanto más si recordamos que el propio Alas reconoció el 26 de mayo de 1888, al inaugurar su serie de ensayos titulados "Revista mínima" en la columnas de La Publicidad, que "en literatura, en política, en ciencia, en cien y cien elementos sociales, la República de los franceses es la nación que más influye en España, y el negarlo es prurito de los que quieren darse tono haciendo alarde de saber inglés, alemán o ruso... aunque no lo sepan"ll. En Solos encontramos una crítica cuyo "modelo de recepción"12 es naturalista, y a la vez unas "Cavilaciones" entre las que se adivina la lectura de Schopenhauer, o cuando menos el buen conocimiento del trabajo de Ribot, La Philosophie de Schopenhauer, que Zola también había leído.

10 Lo recogí en mi tesis doctoral Investigaciones sobre el regeneracionismo liberal en las letras españolas (1860-1905), Barcelona, Universitat de Barcelona, 1987, t. II.

11 Leopoldo Alas "Clarín" (1888). Artículo no recogido hasta la fecha.

12 El concepto "modelo de recepción", que he utilizado en varios trabajos -inicialmente en (Sotelo Vázquez, 1991) - procede de Henri Mitterand. Cf. (1986) y (1990). 
Por otra parte, para 1880 Schopenhauer era el filósofo de moda en Francia y su filosofía "contamine, ou, comme dit alors, morphinise les esprits les plus robustes, à commencer par Zola"i3. Varios datos corroboran el éxito de Schopenhauer en la cultura francesa tan atentamente seguida por Clarín. En 1879 Germer Baillière edita, traducido por Auguste Burdeau, el tomo Le fondament de la morale. De las mismas prensas sale en 1880 una parte de Parerga und Paralipomena bajo el título de Aphorismes sur la sagesse dans la vie, traducidos por Cantacuzàne, y en 1881 otra parte, con el título de Pensées et fragments, traducidos y prologados por Burdeau. Precisamente este tomo fue leído atentamente por Zola, quien tomó notas para la documentación de su novela La Joie de vivre, subrayando la oscilación de la vida entre el dolor y el tedio (el fastidio, según la traducción de Antonio Zozaya) ${ }^{14}$.

A estas decisivas referencias conviene sumar algunas otras posteriores acerca de la recepción de La Joie de vivre (1884), novela en la que se ofrece un rotundo anacronismo que, sin embargo, habla por sí solo de la capital importancia que Schopenhauer alcanzó en los años 80. Me refiero al anacronismo de conceder una influencia - que no tenía - a la filosofía del maestro Frankfurt en la Francia del Segundo Imperio, tiempo de la historia de la novela, como revelan algunos pasajes de la misma ${ }^{15}$. Un último ejemplo de la mitificación de Schopenhauer por parte de la escuela naturalista lo ofrece la sintética reflexión del crítico de Le Figaro, Albert Wolff, militante anti-naturalista, quien escribía en las columnas del periódico conservador (15-II-1886):

"A cette heure, Paris est plein de Schopenhauer en herbes qui rongent les lettres françaises comme la phylloxera dévore les vignes de Bourdeaux"16.

Zola no tuvo una cxcesiva simpatía por Schopenhauer, pero las analogías y las convergencias del naturalismo con el ideario del filósofo alemán son evidentes, como lo fueron en su momento para un crítico tan avisado como Charles Bigot, quien en sendos artículos dedicados a la estética naturalista, aparecidos en la primera mitad del año 1879 en la Revue de Deux Mondes y en la Revista Contemporánea, hablaba del ciclo de los Rougon Macquart como una aplicación de los esquemas filosóficos de Schopenhauer. En la revista francesa decía que Zola entendía la

13. Alain Roger (1997, pág. 346). El trabajo, interesante, contiene sin embargo algunos errores bibliográficos.

14 Las notas pueden leerse en "La documentation de La Joie de vivre", en Émile Zola (1992, t. III, págs. 1625-1626).

15 Prueba evidente, por lo demás, de que el temperamento y el genio del artista tienen una innegable importancia en la teoría de la novela naturalista. Me refiero a pasajes como éste, en el que el narrador - se trata del capítulo final de la novela - describe a Pauline meciendo al pequeño Paul, hijo de Lazare: "Elle berçait le petit Paul, elle riait plus haut, en racontant plaisamment que son cousin l'avait convertie au grand saint Schopenhauer, qu'elle voulait rester fille afin de travaille à la délivrance universelle; et c'était elle, en effet, le renoncement, l'amour des autres, la bonté épandue sur l'humanité Inauvaise." (Émile Zola, 1992, t. IIL, pp. 1296-1297).

16 Apud. René Pierre Colin (1979, pág. 138). 
humanidad como "une grande maladie dont chaque individu est une manifestation pathologique", mientras que en la revista española decía que el ciclo se asemejaba "a una vasta clínica de hospital, en que el novelista, pareciéndose a un profesor, diseca los cadáveres con el escalpelo en la mano, y hace ver, por medio de la autopsia, las lesiones orgánicas que han ocasionado la muerte de cada enfermo"17. Cierto que son otras, además, las fuentes, pero es particularmente relevante que Bigot, el primer crítico que divulgó al Zola naturalista en España, se afanase en mostrar ese paralelismo en las fronteras finales de la década de los setenta.

Clarín tenía, a la altura de la redacción de su tesis doctoral, un conocimiento más bien sumario de Schopenhauer, lo que no le impide aludir a su filosofía para discrepar del pesimismo sistemático que la nutre. Así en la reseña de Marianela (El Solfeo, 14-IV-1878), preguntándose acerca de si Galdós es pesimista, sostiene que el novelista canario no practica el "pesimismo-tesis", aunque su novela está embargada por un pesimismo artístico, sincero y noble, que deviene en mensaje esperanzado. Sin mencionar a Schopenhauer, Clarín opone el "pesimismo sistemático, el desesperado" a las tristezas del arte o de la Naturaleza que "son una forma de esperanza"18. Preocupado por revelar a través del arte, del gran arte, las profundas verdades de la vida (tal el empeño de La Regenta), vedadas a los dogmatismos positivistas, Clarín leyó a Zola al compás que intensificó su curiosidad por el pensamiento de Schopenhauer. Convencido de que el naturalismo no implica el pesimismo, ni tampoco es una derivación literaria de ese ideario filosófico ${ }^{19}$, y sabedor de que el dolor es la evidencia de estar vivo ${ }^{20}$, Clarín cavila alrededor de la filosofía pesimista con aforismos que alumbran premonitoriamente el sentido de su obra maestra de unos años después:

"Los filósofos pesimistas suelen equivocarse en su sistema y en las consecuencias que deducen de los datos recogidos; pero los datos casi siempre son ciertos. Esto es lo más triste del pesimismo" (1891, pág. 88) ${ }^{21}$.

17 Cito los textos de Bigot por Colette Becker, "Préface" a La Joie de vivre (Zola 1992, t. III, pág. 1023). Y Adolfo Sotelo Vázquez (1994 pág. 34-35). Tanto la profesora Becker como yo mismo hemos contextualizado esas notas de Bigot en los trabajos citados.

is Leopoldo Alas "Clarín" (1891, pág. 286). Al cerrar estas reflexiones una nota añadida a la cuarta edición dice: "Esto escribía yo hace diez años, y esto creo hoy finalmente, y esto prueba que las tendencias actuales de mis ensayos críticos y novelescos no obedecen a modas extranjeras, sino a sentimientos y convicciones antiguas y arraigadas" (pág. 287).

19 Cf. Leopoldo Alas "Clarín", "Del Naturalismo" (La Diana, 1-III-1882). Recogido en Sergio Beser (1972, pág. 123).

20. "Toda filosofia que pretenda merecer que la estudie el hombre experimentado, no debe dejar entre lo accesorio la teoría del dolor" [Leopoldo Alas "Clarín", "Más cavilaciones", La Publicidad, 16XII-1880 (1891, pág. 87)].

21 Nótese que el léxico clariniano está impregnado por igual de Schopenhauer y de Zola ("los datos recogidos"). La lectura del naturalismo fue en Alas estímulo para el análisis del pesimismo. 


\section{III}

Que Clarín se interesa por el pensamiento de Schopenhauer al mismo tiempo que se deslumbra con la obra de Zola parece suficientemente constatado. Durante 1884, mientras se anda gestando La Regenta, ocurre un suceso nada irrelevante para la voluntad artística de Alas: ve la luz el tomo La Joie de vivre, perteneciente al ciclo de Les Rougon Macquart. Precisamente la novela de Zola es saludada por la crítica francesa contemporánea como la confirmación de la incidencia de la filosofía pesimista en su gran retablo novelesco. Jules Lemaître sostiene en la primera serie de Les Contemporains que Les Rougon Macquart es "una epopeya pesimista de la animalidad humana", y refiriéndose, en concreto, a la novela recién aparecida escribe (explicando el valor simbólico, de bestia monstruosa y trangresora que tiene el Oceáno): "En La Joie de vivre, el oceáno, primeramente cómplice de los amores y ambiciones de Lázaro, después su enemigo, y cuya victoria acaba por descomponer el débil carácter de este discípulo de Schopenhauer" (Lemaître 1886, t. I, pág. 262). Edouard Rod apunta a comienzos del 84, que Lázaro "es un producto de las ideas pesimistas tan cual circulan entre nosotros" (Rod 1888, pág. 91). En el mismo sentido se manifiesta Guy de Maupassant, quien llega a escribir que "sobre el libro entero planea un pájaro negro con las alas extendidas: la muerte"22. Mientras que, al margen de la crítica periodística, Huysmans, quien publica en 1884 À Rebours, y que "admiraba a Schopenhauer más de lo razonable" — según confesión retrospectiva ${ }^{2.3}$ - escribe a Zola una carta en marzo de 1884 que es, en realidad, una lección sobre Schopenhauer administrada por el discípulo al maestro, en la que se advierte que la lectura que Huysmans ha hecho de La Joie de vivre atina en ver en la novela de Zola dos figuras impregnadas de Schopenhauer (Lazare, impreganado de las ideas del libro segundo de El mundo como voluntad y representación; y Pauline, de las del libro cuarto), y, al mismo tiempo, no se le escapa la vertiente moral de la novela y sus posibles alternativas:

"Quant à Lazare, je le trouve étudié, au point de vue psychologique, de main de maître, mais il y a là une théorie du schopenhauerisme qui ne me semble pas parfaitement exacte. Tout le côté absolument consolant de cette doctrine et antiromantique, anti-Wertheriste, bien que vous en puissez dire, n' y est pas assez, je trouve, exposé. Songez que c'est la théorie de la résignation, la même théorie absolument que celle de L'Imitation de Jésus-Christ, moins la panacée future, remplacée par l'esprit de patience, par le parti pris de tout accepter sans se plaindre, par l'attente bienfaisante de la mort, considérée, ainsi que dans la religion, comme une délivrance et non comme une peur. Je sais bien que vous ne croyez pas au pessimisme et que la préface de Burdeau aux Pensées de Schopenhauer déclare que cet homme prodigieux avait la crainte de la mort

22 Guy de Maupassant, "Émile Zola. La Joie de vivre" (Le Gaulois, 27-IV-1884). Cito por Maupassant (1980, pág. 323).

23. Joris-Karl Huysmans (1984, pág. 104): "Prólogo del autor. Escrito veinte años después de la novela" (1904). Recuérdese, al paso, que Des Esseintes parece una figura encarnada desde el libro tercero de El mundo como voluntad y representación. Cf. Alain Roger (1997, pág. 354). 
-mais, la théorie et plus haute, passe au-dessus de l'homme qui n'appliquait pas à lui-même ses idées, mais, dans l'impossibilité où le gens intelligents se trouvent de croire au catholicisme, ces idées sont, à coup sûr, les plus consolantes, les plus logiques, les plus évidentes qui puissent être. Au fond, si l'on n'est pas pessimiste, il n'y a qu'à être chrétien ou anarchiste; un des trois pour peu qu'on y réfléchisse" 24 .

Es decir, los naturalistas al completo ven en la reciente obra de Zola una poderosa influencia del pensamiento de Schopenhauer, e incluso Huysmans se permite una lectura de orden moral que da en la diana del significado profundo de la novela.

Clarín, que está trabajando en La Regenta y que ha rebajado notablemente el número de artículos que produce su fábrica, escribe a Galdós el 8 de abril de 1884: "Lea sin falta, si no los ha leído, La Joie de vivre y las Cartas de Flaubert". Referencia que hay que completar con el comentario que unas líneas más arriba hacía en la misma carta, y que sorprendentemente armoniza con la lectura que de la novela zolesca hizo Huysmans. Le dice Clarín a Galdós que La Joie de vivre es "un libro tan hermoso, tan grande, tan profundo, tan moral" (Ortega 1964, pág. 216). Clarín, que no escribió comentario crítico alguno de La Joie de vivre, se dio cuenta de inmediato de la excepcional humanidad de la novela de Zola. Con La Regenta en la calle y al aire de la publicación de Lo prohibido le escribe a Galdós (3-VII1885):

"Lo que pasa con Lo prohibido me ha pasado con La Joie de vivre de Zola, que me pareció una de sus mejores novelas y solo a Sarcey vi entusiasmado con ella. Es Germinal más grandioso y fuerte, pero no más profundo y acaso menos verdadero" (Ortega 1964, pág. 233).

La transparente sinceridad de la novela, que abordaba la injusticia de la existencia humana con notoria amargura, dejaba entrever una serie de razones para seguir viviendo y esperando (Pauline es el verdadero mensaje moral de la novela). A Clarín no se le pudo escapar este aspecto de La Joie de vivre al que Zola dedicaría en parte Le Docteur Pascal (1893), la novela final de la serie Les Rougon Macquart, y en la que Alas atisbó -como en L'Argent (1891) y La Débâcle (1892), "fugas de idealidad, horizontes de misterio y tal vez de esperanza que no había en Pot Bouille, en L'Assommoir, en Nana, etc"26; propuesta ya anunciada en su anterior reseña de La Débâcle, en la que, aludiendo a Schopenhauer y a Leopardi, sostiene que Zola acentúa ciertas tendencias de la novela en "el sentido de la esperanza, de la idealidad en la virtud, no en los pormenores, no en el falso idealismo (verdaderamente grotesco) de mejorar falseándola la realidad aparente ${ }^{\text {"27. }}$. De esas

\footnotetext{
24 Cito la carta de Huysmans por Émile Zola, "Dossiers des oeuvres" (1992, t. III, pág. 1670).

25 Soledad Ortega (1964, pág. 218).

26 Leopoldo Alas "Clarín", "Lecturas", La llustración Ibérica (23-XII-1893).

27 Leopoldo Alas "Clarín", "La Debacle", Los lunes de El Imparcial (18-VII-1892).
} 
tendencias sin duda participaba, años antes, La Joie de vivre, novela que resultó fascinante para quien en 1880 había escrito el siguiente aforismo: "Sólo la virtud tiene argumentos poderosos contra el pesimismo"28.

Los estímulos y las incitaciones que Clarín ha aprendido en Schopenhauer y en Zola (especialmente en La Joie de vivre) debían tener un papel relevante en la construcción del desenlace de su obra maestra. La íntima atención que les prestó debía materializarse en la intención de La Regenta. El colofón del presente artículo quiere mostrar lacónicamente esas latentes intertextualidades.

Si La Regenta es una novela ejemplar de la experimentación artística del naturalismo, lo es, entre otras razones (esta que gloso es de orden temático-moral) porque la escritura de Clarín aloja en el seno de una sociedad, Vetusta, amargamente hipócrita y egoísta, una contradicción romántica, el alma poética y soñadora de Ana Ozores. Desde el punto de vista de las estrategias autoriales, ideológicas y estéticas, lo que Clarín narra y describe en La Regenta es el intento, objetiva e inexorablemente condenado al dolor, de vivir siendo mercancía y sentir la necesidad de vivir para el alma. O dicho con las palabras magistrales de Gonzalo Sobejano: "la intención moral de La Regenta sólo puede verse, al resplandor de su final, como la demostración de la lucha inacabable de los mejores: el dolor de no poder alcanzar nunca los valores supremos cuya búsqueda es el único sentir de su existencia" (Sobejano 1989, pág. 720). Siendo para ello conveniente dejar a un lado el dogma del impersonalismo, del que el propio Clarín explicó sus límites refiriéndose a Flaubert:

"Leo a Flaubert en sus novelas, y a pesar de su programa de impersonalismo, cumplido casi al pie de la letra, y sin que haya en esto contradicción, veo en esas novelas todo lo que necesito para conocer las ideas, el carácter espiritual, hasta el temperamento del autor con relación a los más graves asuntos. (...) ¿Qué libro habrá más impersonal (técnicamente) que Bouvard et Pécuchet? Y sin embargo, se podría reconstruir sólo con él, no las opiniones de Flaubert, pero sí los rasgos principales de su espíritu en las múltiples relaciones del pensar, del sentir y del querer con los más interesantes aspectos de la realidad, en cuanto ésta puede estar en contacto con el alma"29.

Me explicaré. El dolor se convierte en la única realidad en el inmenso mar de dudas y vacilaciones en el que vive sumida Anita tras el duelo, la muerte de don Víctor y la huida cobarde y canalla de don Álvaro. Las reflexiones de la protagonista revelan en esta situación la estrategia generadora de la intención final de la novela. El pasaje primero y primordial, el principio del final, es una fascinante combinación de discursos narrativos (discurso narrativizado, discurso restituido y discurso transpuesto en estilo indirecto libre):

28 Leopoldo Alas "Clarín" (1891, pág. 86).

29 Leopoldo Alas "Clarín", "Los pazos de Ulloa, por Emilia Pardo Bazán", La Opinión, 30-XI1886 (en 1989, pág. 230). 
"Con el alimento y la nueva fuerza reapareció el fantasma del crimen. ¡Oh, qué evidente era el mal! Ella estaba condenada. Esto era claro como la luz. Pero a ratos, meditando, pensando en su delito, en su doble delito, en la muerte de Quintanar sobre todo, al remordimiento, que era una cosa sólida en la conciencia, un mal palpable, una desesperación definida, evidente, se mezclaba, como una niebla que pasa por delante de un cuerpo, un vago terror más temible que el infierno, el terror de la locura, la aprensión de perder el juicio; Ana dejaba de ver tan claro su crimen; no sabía quién discutía dentro de ella, inventaba sofismas sin contestación, que no aliviaban el dolor del remordimiento, pero hacían dudar de todo, de que hubiera justicia, crímenes, piedad, Dios, lógica, alma... Ana. 'No, no hay nada - decía aquel tormento del cerebro-; no hay más que un juego de dolores, un choque de contrasentidos que pueden hacer que padezcas infinitamente; no hay razón para que tenga límites esta tortura del espíritu, que duda de todo, de sí mismo también, pero no del dolor que es lo único que llega al que dentro de ti siente, que no se cómo es ni lo que es, pero que padece, pues padeces.'

Estas logomaquias de la voz interior, para la enferma eran claras, porque no hablaba así en sus adentros sino en vista de lo que experimentaba; todo esto lo pensaba porque lo observaba dentro de sí; llegaba a no creer más que en su dolor" (Alas 1988, págs. 522-523).

Pasaje del discurso narrativo que alcanza toda su relevancia, su inmanencia y su trascendencia, a la luz que ofrecen los textos a los que he aludido (todos en la órbita del naturalismo) y de los que han quedado implícitos procedentes de la summa de los discursos teórico y crítico de Alas. Especialmente relevante para la experimentación artística de La Regenta es el de Schopenhauer, quien sostenía que por su origen y por su esencia la voluntad está condenada al dolor, que en la existencia cotidiana, en la prosa del mundo, se combina con el hastío y el tedio. He ahí las coordenadas de la trayectoria vital de Ana: hastío, tedio, aburrimiento, vacíos, silencios, dolor.

El proceso de recuperación de Ana, de mayo a octubre, con el denominador común de un sinfín de dolores, parece pautado en algunos momentos por el libro cuarto de El mundo como voluntad y representación. Ana debe anular lo mejor de su alma, sus ansias íntimas, evitar los razonamientos y vivir desde las apariencias, desde lo inauténtico:

"Aborrecía los libros, fuesen los que fuesen; todo raciocinio la llevaba a pensar en sus desgracias; el caso era no discurrir. Y a ratos lo conseguía. Entonces se le figuraba que lo mejor de su alma se dormía, mientras quedaba en ella despierto el espíritu suficiente para ser tan mujer como tantas otras" (Alas 1988, págs. 527-528).

Antes de que llegue octubre y asistamos a la escena final de la novela, sabemos, mediante un narrador muy próximo a la conciencia de Ana, del marasmo del alma de la protagonista: de un lado, de su inacabable dolor; de otro, de su progresivo desvanecimiento en la nada de la rutina vulgar y anodina: 
"Ahora nada; huir del dolor y del pensamiento. Pero aquella piedad mecánica, aquel rezar y oír misa como las demás le parecía bien, le parecía la religión compatible con el marasmo de su alma. Y además, sin darse cuenta de ello, la religión vulgar (que así la llamaba para sus adentros) le daba un pretexto para faltar a su promesa de no salir jamás de casa" (Alas 1988, pág. 532).

Tan sólo queda esperar el final, al que aparentemente Ana se desliza desde la "religión vulgar", desde la anulación de la voluntad. Pero no es así: Ana vuelve a la antigua patria, a la catedral de Vetusta, y se produce el despertar de la voluptuosidad de los sentidos, de las desazones de su alma, y de nuevo siente "lo más íntimo de su deseo y de su pensamiento, ella misma" (Alas 1988, pág. 534). La voluntad, el dolor, el deseo, "el hambre y la sed de lo infinito y de lo eterno ${ }^{30}$ desembocan en la nada, en la escenificación de la tragedia de la soledad de Ana, en la escena final de La Regenta.

\section{BIBLIOGRAFÍA CITADA}

ALAS "CLARÍN", Leopoldo. 1878. "El derecho y la moralidad", Revista Europea, núm. 243 (20 de octubre).

- 1888. "Revista mínima. Introito", en La Publicidad, 20 de mayo.

- 1891. Solos, Madrid, Fernando Fe (4 ed.).

- 1892. "La Debacle", Los lunes de El Imparcial, 18 de julio.

- 1893. "Lecturas", La Ilustración Ibérica, 23 de diciembre.

- 1973. Obra olvidada, ed. de Antonio Ramos Gascón, Madrid, Júcar.

- 1988. La Regenta, ed. de Gonzalo Sobejano, Madrid, Castalia, 2 vols.

- 1989. Nueva Campaña (1887), ed. de Antonio Vilanova, Barcelona, Lumen.

BAILLOT, A.. 1927. Influence de la philosophie de Schopenhauer en France (I8601900), Paris, J. Vrin.

BESER, Sergio. 1972. Leopoldo Alas: teoria y crítica de la novela española, Barcelona, Laia.

COLIN, Jean Pierre. 1979. Schopenhauer en France. Un mythe naturaliste, Lyon, Presses Universitaires de Lyon.

30 La pauta filosófica del proceso final de Ana (sin que ello suponga una convergencia de intenciones) se encuentra en los capítulos LVI al LVIII del libro tercero de El mundo como voluntad y representación. No obstante, remito a un fragmento de un ensayo, El dolor, de Urbano González Serrano, publicado en fechas relativamente alejadas de la novela de Alas (1894, pág. 253). 
DEL PEROJO, José. 1875. “Arturo Schopenhauer”, Revista Europea, núm. 64 (16 de mayo).

DE LA REVILLA, Manuel. 1875. "El neo-kantismo en España. Ensayos sobre el movimiento intelectual en Alemania, por don José del Perojo", Revista de España, XLVII (13 de noviembre).

DE MAUPASSANT, Guy. 1980. Chroniques 2, Paris, Union Génerale d'Editions.

GONZÁLEZ SERRANO, Urbano. 1881. "El movimiento intelectual en Alemania, por D. José del Perojo", Ensayos de crítica y de filosofía, Madrid, Aurelio J. Alaria.

- 1894. En pro y en contra (Críticas), Madrid, Victoriano Suárez.

GREGOR-DELLIN, Martín. 1983. Richard Wagner, Madrid, Alianza Editorial.

HUYSMANS, Joris-Karl. 1984. À Rebours, trad. de Juan Herrero, Madrid, Cátedra.

LEMAîTRE, Jules. 1886. "Ëmile Zola”, Les Contemporains, Paris, H. Lecène et H. Oudin, vol. I.

LISSORGUES, Yvan. 1989. Clarín político I, Barcelona, Lumen.

MITTERAND, Henri, 1986. Zola et le naturalisme, Paris, PUF.

- 1990. Zola. L'histoire et la fiction, Paris, PUF.

ORTEGA, Soledad, ed. 1964. Cartas a Galdós, Madrid, Revista de Occidente.

RAYMOND, Didier. 1979. Schopenhauer, Paris, Seuil.

ROD, Edouard. 1888. Etudes sur le XIX' Siècle, Paris, Perrin.

ROGER, Alain. 1997. "Schopenhauer, Huysmans et Zola", Schopenhauer, L'Herne, núm. 69, ed. de Jean Lefranc.

SCHOPENHAUER, Arturo. 1984. "Metaphysique de l'amour", Le monde comme volonté et comme représentation, trad. de A. Burdeau, ed. de Richard Ross, Paris, PUF.

SOBEJANO, Gonzalo. 1989. "La Regenta: de su final a su finalidad", Homenaje al profesor Antonio Vilanova [Adolfo Sotelo Vázquez (coord.)/ Marta Cristina Carbonell (ed.)], vol. II, Barcelona, Universitat de Barcelona.

SOTELO VÁZQUEZ, Adolfo. 1991. Galdós, novelista, Barcelona, PPU.

- 1994. "José del Perojo y la Revista Contemporánea", Cuadernos Hispanoamericanos, núm. 523, págs. 19-35.

ZOLA, Émile. 1992. Les Rougon Macquart, t. III, ed. de Colette Becker, Paris, Robert Laffont (Bouquins). 